\title{
Adenylylsulphate reductase from the sulphate- reducing archaeon Archaeoglobus fulgidus: cloning and characterization of the genes and comparison of the enzyme with other iron-sulphur flavoproteins
}

\author{
Norbert Speich, ${ }^{1}+$ Christiane Dahl, ${ }^{1}$ Peter Heisig, ${ }^{1}$ Albrecht Klein, ${ }^{2}$ \\ Friedrich Lottspeich, ${ }^{3}$ Karl O. Stetter ${ }^{4}$ and Hans G. Trüper ${ }^{1}$
}

Author for correspondence: H. G. Trüper. Tel: +49228 732320. Fax: +49228 737576.

\footnotetext{
1 Institut für Mikrobiologie \& Biotechnologie, Rheinische FriedrichWilhelms-Universität Bonn, Meckenheimer Allee 168, 53115 Bonn, Germany

2 Institut für Molekulargenetik, FB Biologie, PhilippsUniversität Marburg, 35037 Marburg, Germany

3 Max-Planck-Institut für Biochemie, Am Klopferspitz 18a, 82143 Martinsried, Germany

4 Institut für Mikrobiologie, Universität Regensburg, Universitätsstr. 31, 93053 Regensburg, Germany
}

\begin{abstract}
Adenylylsulphate (adenosine-5'-phosphosulphate, APS) reductase from the extremely thermophilic sulphate-reducing archaeon Archaeoglobus fulgidus is an iron-sulphur flavoprotein containing one non-covalently bound flavin group, eight non-haem iron and six labile sulphide atoms per molecule. Reevaluation of the enzyme structure revealed the presence of two different subunits with molecular masses of 80 and $18.5 \mathrm{kDa}$. The subunits are arranged in an $\alpha_{2} \beta$ subunit structure. We have cloned and sequenced a $2.7 \mathrm{~kb}$ segment of DNA containing the genes for the $\alpha$ and $\beta$ subunits, which we designate aprA and aprB, respectively. The two genes are separated by 17 bp and localized in the order aprBA. While a putative promoter could not be identified in the vicinity of aprBA a probable termination signal was found just downstream of the translation stop codon of aprA. The codon usage for aprBA shows strong preferences for $G$ and $C$ in the third codon position. aprA encodes a $73.3 \mathrm{kDa}$ polypeptide, which shows significant overall similarities with the flavoprotein subunits of the succinate dehydrogenases from Escherichia coli and Bacillus subtilis and the corresponding flavoprotein of $E$. coli fumarate reductase. Part of the homologous peptide stretches could be assigned to domains that are involved in the binding of the substrate or of the FAD prosthetic group. aprB encodes a 17.1 kDa polypeptide representing an iron-sulphur protein, seven cysteine residues of which are arranged in two clusters typical of ligands of the iron-sulphur centres in $\left\{\left[\mathrm{Fe}_{3} \mathrm{~S}_{4}\right]\left[\mathrm{Fe}_{4} \mathrm{~S}_{4}\right]\right\}$ 7-Fe ferredoxins.
\end{abstract}

Keywords: Archaeoglobus fulgidus, adenylylsulphate reductase, dissimilatory sulphate reduction, iron--sulphur protein, flavoprotein

\section{INTRODUCTION}

During the past decade the genes for several proteins such as DNA-dependent RNA polymerase, elongation factor 2 and glyceraldehyde-3-phosphate dehydrogenase have been used to point out the phylogenetic relationships

†Present address: Institut für Humangenetik, Philipps-Universität Marburg, Germany.

Abbreviations: APS, adenosine-5'-phosphosulphate; FRD, fumarate reductase; SDH, succinate dehydrogenase.

The EMBL accession number for the novel sequence data reported in this paper is $\mathrm{X} 63435$. between the three primary domains, the Archaea, the Bacteria and the Eucarya (Zillig et al., 1989; Schröder \& Klink, 1991). Because the utilization of sulphur compounds for energy-yielding processes seems to have developed very early during prokaryotic evolution (Trüper, 1982; Schidlowski, 1986) we intend to expand such analyses to bacterial and archaeal sulphurmetabolizing organisms and initiated this work with dissimilatory sulphate reducers (Dahl et al., 1993). While the ubiquitous presence of bacterial desulfuricants in nature has long been observed (Beijerinck, 1895) the discovery of the first archaeal species of this physiological group took until 1987 when K. O. Stetter and co-workers described the extremely thermophilic Archaeoglobus ful- 
gidus (Achenbach-Richter et al., 1987; Stetter, 1988). The organism was isolated from a submarine volcanic hot spring and has an optimum growth temperature of $83{ }^{\circ} \mathrm{C}$.

A. fulgidus has been shown to contain the complete pathway for dissimilatory sulphate reduction known from eubacteria, which requires the sequential action of the enzymes ATP sulphurylase, APS reductase and sulphite reductase (Speich \& Trüper, 1988; Dahl et al., 1990). As a key enzyme in dissimilatory sulphur metabolism APS reductase has not only been found in all dissimilatory sulphate-reducing prokaryotes but also in several chemolithoautotrophic and photolithoautotrophic sulphuroxidizing bacteria of different phylogenetic positions (Trüper, 1989; Takakuwa, 1992). In common with most other APS reductases studied so far the enzyme from $A$. fulgidus has a molecular mass of $160000 \mathrm{Da}$ and contains FAD, non-haem iron and acid-labile sulphide (Speich \& Trüper, 1988). The similarity of bacterial and archaeal APS reductases indicates a strong conservation of structure and function in this protein, making it an ideal candidate for phylogenetic studies.

In this report we mainly intend to supply basic information about this widespread enzyme. We re-evaluate the structure of APS reductase from $A$. fulgidus and describe the cloning and sequencing of the genes encoding the enzyme. The first sequence of an APS reductase should, however, not only contribute to a better understanding of dissimilatory sulphur metabolism but provide the basis for future work on the evolution of this enzyme.

\section{METHODS}

Bacterial strains and vectors. A. fulgidus DSM $4304^{\mathrm{T}}$ was grown and harvested as described earlier (Stetter et al., 1987). E. coli XL1-Blue, which is end $A 1$ supE44 bsdR $17\left(r^{-} m^{+}\right)$thi $\lambda^{-}$ $\operatorname{rec} A 1$ gyr $A 96$ lac $^{-}\left[\mathrm{F}^{\prime}\right.$ pro $A B$ lacI ${ }^{\mathrm{q}} Z \Delta \mathrm{M} 15 \mathrm{Tn} 10\left(\right.$ tet $\left.\left.^{r}\right)\right]$, was the host for the lambda ZAPII (Stratagene) and pBluescript plasmid derivatives and $E$. coli strain P2PLK17 [supE lac mor $A$ morB $b s d \mathrm{R} \operatorname{gal}(\mathrm{P} 2$ lysogen)] was the host for lambda FixII (Stratagene) derivatives.

E. coli XL1-Blue was grown in LB medium (Sambrook et al., 1989) with $12.5 \mu \mathrm{g}$ tetracycline $\mathrm{ml}^{-1}$, which was supplemented with $100 \mu \mathrm{g}$ ampicillin $\mathrm{ml}^{-1}$ for plasmid containing derivatives. Lambda phage derivatives were plated in top agar consisting of NZCYM (Sambrook et al., 1989) containing 0.7\% agarose. 5Bromo-4-chloro-3-indolyl $\beta$-D-galactopyranoside and isopropyl $\beta$-D-thiogalactopyranoside were included in solid media to identify recombinant phage and plasmids containing inserts in the $\alpha$ portion of lac $Z$.

Purification of APS reductase. APS reductase was assayed in the direction of APS formation from sulphite and AMP with ferricyanide as electron acceptor (Speich \& Trüper, 1988). Enzyme activity was monitored at $85^{\circ} \mathrm{C}$. Crude extracts were prepared as described previously (Speich \& Trüper, 1988). Ammonium sulphate was added to the ultracentrifugation supernatant to $50 \%$ saturation at $0{ }^{\circ} \mathrm{C}$. The precipitated protein was separated from the supernatant by ultracentrifugation $(140000 \mathrm{~g}, 1 \mathrm{~h})$ and discarded. The supernatant was applied to a column of Phenylsepharose CL-4B FastFlow (low substituted) $\left(2.6 \times 17 \mathrm{~cm}\right.$; flow rate $\left.3 \mathrm{ml} \mathrm{min}^{-1}\right)$ equilibrated with $50 \mathrm{mM}$ Tris $/ \mathrm{HCl}, \mathrm{pH} 8 \cdot 0$, containing ammonium sulphate at
$50 \%$ saturation. After washing the column with $40 \%$ ammonium sulphate in the same buffer the enzyme was eluted with a linear gradient of ammonium sulphate between $40 \%$ and $0 \%$ saturation $(800 \mathrm{ml})$. APS reductase eluted between $16 \%$ and $9 \%\left(\mathrm{NH}_{4}\right)_{2} \mathrm{SO}_{4}$. The active enzyme fractions were pooled and desalted by dialysis against $50 \mathrm{mM}$ Tris $/ \mathrm{HCl}, \mathrm{pH} 8 \cdot 0$, followed by chromatography on Q-Sepharose FastFlow $(1.6 \times 10 \mathrm{~cm}$; flow rate $2 \mathrm{ml} \mathrm{min}^{-1}$ ) equilibrated in $50 \mathrm{mM}$ Tris $/ \mathrm{HCl}, \mathrm{pH} \mathrm{8.0.}$ With a gradient from $0-400 \mathrm{mM} \mathrm{NaCl}(600 \mathrm{ml})$ APS reductase was recovered at $240-280 \mathrm{mM} \mathrm{NaCl}$. Fractions containing the enzyme were combined, desalted by dialysis and further purified by chromatography on MonoQ HR $5 / 5$. The column was equilibrated with $50 \mathrm{mM}$ Tris $/ \mathrm{HCl}, \mathrm{pH} 8.0$, and after application of the protein washed with the same buffer containing $100 \mathrm{mM} \mathrm{NaCl}$. Via a linear gradient from $100 \mathrm{mM}$ to $300 \mathrm{mM}$ $\mathrm{NaCl}(20 \mathrm{ml})$ APS reductase was retrieved at $190-230 \mathrm{mM}$ $\mathrm{NaCl}$ with a purity coefficient of $5 \cdot 0\left(A_{280} / A_{390}\right)$ and a specific activity of $2 \cdot 3 \mu \mathrm{mol} \mathrm{APS} \mathrm{min}^{-1} \mathrm{mg}^{-1}$.

Polyacrylamide gel electrophoresis. SDS-PAGE was performed according to the procedure of Laemmli (1970) and bands were stained with Coomassie Blue.

Protein sequencing. Purified native APS reductase of $A$. fulgidus was directly sequenced by automated Edman degradation in a Beckman sequencer. For amino-terminal sequencing of the $\alpha$ subunit the contents of a $12.5 \%$ SDS-polyacrylamide gel loaded with $50 \mu \mathrm{g}$ APS reductase were electrophoretically transferred onto a siliconized glass filter and directly subjected to automated Edman degradation with an Applied Biosystems $477 \mathrm{~A}$ gas-phase sequencer.

Recombinant DNA techniques. All general cloning techniques were performed according to standard methods (Sambrook et al., 1989). Chromosomal DNA of $A$. fulgidus was obtained by lysis with $0.5 \%$ SDS as described elsewhere (Dahl et al., 1993). The mixture was extracted with phenol and chloroform and the DNA was purified by $\mathrm{CsCl}$ density gradient centrifugation. Exonuclease III deletion clones were prepared using the nested deletion kit from Pharmacia and sequenced with the chaintermination method (Sanger et al., 1977) using T7 Polymerase and $\left[\alpha_{-}{ }^{32} \mathrm{P}\right] \mathrm{dATP}$ or Taq polymerase and dye-labelled dideoxynucleotides. Dye-labelled DNA was analysed with a 373 A DNA Sequencer from Applied Biosystems. The DNA sequence data were aligned and analysed with the DNASIS software from Pharmacia.

Construction of DNA libraries. A complete library of chromosomal DNA of $A$. fulgidus was constructed as described by Dahl et al. (1993). A second $A$. fulgidus library was constructed from size-fractionated HindIII fragments of $1-1.5 \mathrm{~kb}$, which were filled-in with dATP and dGTP using the DNA polymerase Klenow fragment and ligated into lambda ZAPII, which had been digested with $S p e$ I and filled-in with dCTP and dTTP. This library was screened directly without amplification. pBluescript derivatives were prepared from lambda ZAPII by using the R408 single-stranded helper phage according to the protocol provided by Stratagene.

Hybridizations. DNA probes for Southern blot experiments and screening of phage libraries were radioactively labelled by the random-priming method (Feinberg \& Vogelstein, 1983) with $\left[\alpha-{ }^{32} \mathrm{P}\right] \mathrm{dCTP}$. Hybridizations were performed overnight at $68^{\circ} \mathrm{C}$ in $5 \times \mathrm{SSC}(1 \times \mathrm{SSC}$ is $0.15 \mathrm{M} \mathrm{NaCl}, 15 \mathrm{mM}$ sodium citrate, $\mathrm{pH} 8.0$ ), $0.02 \%$ polyvinylpyrrolidone, $0.02 \%$ Ficoll, $0 \cdot 1 \%$ SDS, containing $100 \mu \mathrm{g}$ nicked and denatured calf thymus DNA ml$l^{-1}$. Membranes and filters were washed twice for $15 \mathrm{~min}$ each at room temperature in $2 \times \mathrm{SSC}, 0.1 \% \mathrm{SDS}$, and then three times for $15 \mathrm{~min}$ each at $68^{\circ} \mathrm{C}$ in $0.1 \times \mathrm{SSC}, 0 \cdot 1 \% \mathrm{SDS}$. 
Oligonucleotide probes were radioactively labelled by $\mathrm{T} 4$ polynucleotide kinase with $\left[\gamma_{-}{ }^{32} \mathrm{P}\right]$ ATP. Hybridizations were carried out at $42{ }^{\circ} \mathrm{C}$ overnight in the solution described above. The membranes were washed four times for $15 \mathrm{~min}$ each at $42{ }^{\circ} \mathrm{C}$ in $5 \times \mathrm{SSC}, 0 \cdot 1 \%$ SDS.

Calculations. The amino acid sequences were analysed on the Convex at the DKFZ Heidelberg using the FASTA program (Devereux et al., 1984) and the Swiss-Prot Protein Data Base (EMBL, Heidelberg).

\section{RESULTS AND DISCUSSION}

\section{Purification of APS reductase and re-evaluation of the enzyme structure}

APS reductase from $A$. fulgidus has been described as an iron-sulphur flavoprotein consisting of two identical $80 \mathrm{kDa}$ subunits (Speich \& Trüper, 1988). We developed an improved purification scheme that takes advantage of the high resolution of FPLC, thereby eliminating the need for preparative isoelectric focusing. The purified enzyme exhibited a specific activity of $2 \cdot 3 \mathrm{U} \mathrm{mg}^{-1}$ compared to the $2.39 \mathrm{U} \mathrm{mg}^{-1}$ obtained with the original purification procedure. When analysed by SDS-PAGE the APS reductase preparations were found to contain a Coomassie-stainable band with a mobility corresponding to a molecular mass of $\sim 18.5 \mathrm{kDa}$ in addition to the $80 \mathrm{kDa}$ polypeptide (Fig. 1). Subunits of comparable size have also been described for the APS reductases from Desulfovibrio vulgaris, Desulfovibrio gigas and Thermodesulfobacterium mobilis (Bramlett \& Peck, 1975; Fauque et al., 1986; Kremer et al., 1988; Lampreia et al., 1990). By integration of densitometric scans and correction for molecular mass a stoichiometry

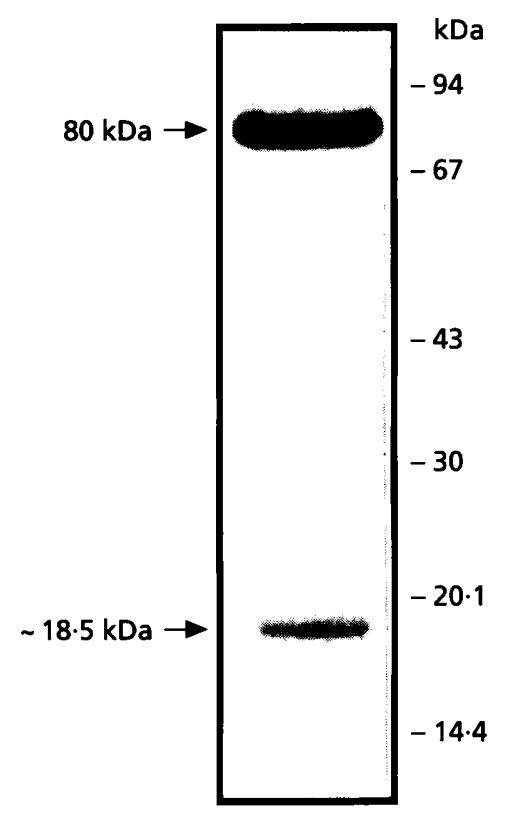

Fig. 1. SDS-PAGE of purified A. fulgidus APS reductase. A $2 \mu \mathrm{g}$ sample of APS reductase was applied to the gel. Molecular masses of markers are indicated. of $2.5: 1$ was obtained for the $80 \mathrm{kDa}(\alpha)$ to $18.5 \mathrm{kDa}(\beta)$ subunits. Together with the apparent molecular mass of the holoenzyme, i.e. 160000 , an $\alpha_{2} \beta$ structure is suggested for the native archaeal APS reductase. The small subunit is lost during isoelectric focusing and is not essential for enzyme activity with ferricyanide as an artificial electron acceptor since APS formation (the enzyme is assayed in the unphysiological direction of APS formation) was proven for enzyme preparations lacking the $18.5 \mathrm{kDa}$ peptide (Speich \& Trüper, 1988). The peptide might, however, be necessary for reaction of APS reductase with its in vivo electron donor. Cloning and sequencing (see below) revealed that the two genes encoding the two different subunits of $A$. fulgidus APS reductase are separated by only $17 \mathrm{bp}$ and are probably localized in the same operon, indicating that the small subunit is likely to be an integral part of the enzyme.

\section{Cloning and nucleotide sequence analysis of the genes for APS reductase}

Amino-terminal sequencing of native APS reductase gave two different sequences of 24 and 5 residues. These two sequences could unambiguously be distinguished on the basis of their relative yields which were close to $2: 1$. Peptide sequence analysis of the $\alpha$ subunit alone gave an amino acid sequence identical to the major sequence obtained for the native enzyme.

A mixture of 128 different 20 -mer oligonucleotides, which was designed from residues 3 to 9 (YYPKKYE) of the amino-terminus of the $\alpha$ subunit, was used to analyse Southern blots of $A$. fulgidus DNA. A single hybridizing band at $1.3 \mathrm{~kb}$ was detected for HindIII-digested DNA. Therefore a non-amplified $\lambda$ ZAPII library of $1-1.5 \mathrm{~kb}$ HindIII fragments was screened with the same probe. One of the 1500 recombinant clones from the library gave a positive signal and was found to contain a $1.3 \mathrm{~kb}$ insert which was subsequently cloned into pBluescript I SK. This clone was designated pARS1. A $697 \mathrm{bp}$ length of the $3^{\prime}$-terminus of the pARS1 insert was sequenced on both strands and found to carry an open reading frame (ORF) of $453 \mathrm{bp}$ encoding a 150 residue, $17 \cdot 1 \mathrm{kDa}$ peptide. Amino acids 2-6 of this peptide match the minor sequence obtained by Edman degradation of native APS reductase, indicating that the corresponding ORF is the gene for the $\beta$ subunit, which we designate $a p r B$. Downstream (17 bp) of $a p r B, 138 \mathrm{bp}$ of the $5^{\prime}$-terminus of a second ORF were detected encoding the complete chemically determined amino-terminal amino acid sequence of the $\alpha$ subunit of APS reductase. These findings indicated that this truncated ORF was part of the gene for the $\alpha$ subunit, which we designate $\operatorname{apr} A$. In order to clone the complete gene the amplified $\lambda$ FixII library of $A$. fulgidus (Dahl et al., 1993) was screened with the radioactively labelled $1.3 \mathrm{~kb}$ HindIII fragment as a probe. Of 20000 recombinant clones from this library, 10 gave positive signals and were found to contain the same $14 \mathrm{~kb}$ insert.

The nucleotide sequence of both strands of a $2720 \mathrm{bp}$ portion of the phage insert was determined (Fig. 2). In 
(1)

ATACCTCCACCAGATATAG

20

90

160

230

300

(77)

370

440

510

580

650

720

(61)

790

(84)

860

(107)

930

1000

(154)

1070

(177)

1140

(201)

1210

(224)

1280

(247)

1350

(271)

1420

(294)

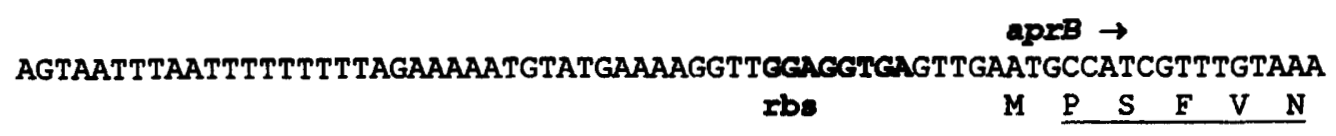
CCCGGAAAATGTGACGGATGTAAGGCGTTGGAGAGAACGGCGTGTGAGTACATCTGCCCCAACGACTTG $\begin{array}{lllllllllllllllllllllll}P & E & K & C & D & G & C & K & A & L & E & R & T & A & C & E & Y & I & C & P & N & D & L\end{array}$ ATGACACTCGATAAAGAGAAGATGAAAGCGTACAACAGAGACCCGGACATGTGCTGGGAGTGCTACAGCT $\begin{array}{llllllllllllllllllllllll}M & T & L & D & K & E & K & M & K & A & Y & N & R & D & P & D & M & C & W & E & C & Y & S & C\end{array}$ GTGTTAAGATGTGCCCGCAGGGGCAAATTGACGTGAGAGGCTACGTGGACTACTCCCCGCTTGGCGGTGC $\begin{array}{lllllllllllllllllllllll}V & K & M & C & P & \& & G & \& & I & D & V & R & G & Y & V & D & Y & S & P & I & G & G & A\end{array}$ CTGTGTGCCAATGAGAGGAACCTCAGACATCATGTGGACGGACAAGTACAGAAACGGAAAGGTTCTGAGG $\begin{array}{lllllllllllllllllllllll}C & V & R & M & R & G & T & S & D & I & M & Y & T & D & K & Y & R & N & G & K & V & L & R\end{array}$ TTCAAGTTCGCCATCAGAACAACCCCGTGGGGCTCAATTCAGCCCTTCGAGGGATTCCCTGAGCCGACCG $\begin{array}{lllllllllllllllllllllllll}\mathbf{F} & \mathbf{K} & \mathbf{F} & \mathbf{A} & \mathbf{I} & \mathbf{R} & \mathbf{T} & \mathbf{T} & \mathbf{P} & \mathbf{W} & \mathbf{G} & \mathbf{S} & \mathbf{I} & \boldsymbol{Q} & \mathbf{P} & \mathbf{F} & \mathbf{E} & \mathbf{G} & \mathbf{F} & \mathbf{P} & \mathbf{E} & \mathbf{P} & \mathbf{T} & \mathbf{E}\end{array}$ AGGAGGCATTGAAGAGCGAACTGCTTGCTGGAGAACCCGAGATTATTGGAACGAGCGAGTTCCCGCAGGT $\begin{array}{lllllllllllllllllllllll}E & A & \text { L } & \text { K } & \text { S } & \text { E } & \text { L } & \text { L } & \text { A } & \text { G } & \text { E } & \text { P } & \text { E } & \text { I } & \text { I } & G & \text { T } & \text { S } & \text { E } & \text { F } & \text { P } & Q & V\end{array}$ apra $\rightarrow$ AAAGAAGAAGGCTTAAAGgTGACGTEGTAGAAATGGTATATTATCCGAAAAAGTATGAGTTGTATAAGGC

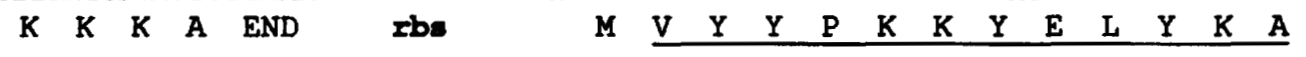
AGATGAAGTGCCGACAGAGGTTGTGGAGACGGACATCTTGATTATCGGAGGAGGTTTCTCCGGCTGTGGT $\begin{array}{llllllllllllllllllllllll}D & E & V & P & T & E & V & V & E & T & D & I & \text { L } & I & I & G & G & G & F & S & G & C & G\end{array}$

FindIII

GCAGCGTACGAGGCTGCCTACTGGGCAAAGGTTGGCGGTTTGAAGCTTACGCTTGTTGAGAAAGCAGCAG $\begin{array}{llllllllllllllllllllllll}A & A & Y & E & A & A & Y & \boldsymbol{H} & A & K & V & G & G & \text { L } & K & \text { L } & T & \text { L } & \text { V } & \text { E } & \text { K } & A & A & V\end{array}$ TTGAGAGAAGCGGAGCTGTTGCCCAGGGTCTTTCAGCCATTAACACATACATCGACCTTACCGGCAGGTC $\begin{array}{llllllllllllllllllllllll} & E & R & S & G & A & V & A & Q & G & I & S & A & I & N & T & Y & I & D & L & T & G & R & S\end{array}$ CGAGAGGCAGAACACCCTTGAGGATTACGTCAGATACGTCACCCTCGACATGATGGGATTGGCGAGAGAG

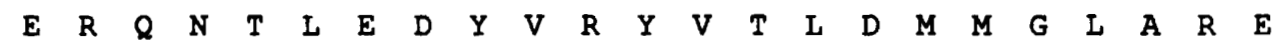
GACCTTGTTGCTGACTACGCAAGGCATGTTGACGGAACGGTCCACCTCTTCGAGAAGTGGGGACTGCCCA $\begin{array}{llllllllllllllllllllllll}D & I & V & A & D & Y & A & R & H & V & D & G & T & V & H & I & F & E & K & W & G & I & P & I\end{array}$ TCTGGAAGACTCCCGATGGGAAGTACGTCAAGAGAGGGACAGTGGCAGATAATGATTCACGGGTGAGAGC $\begin{array}{lllllllllllllllllllllll}W & K & T & P & D & G & K & Y & V & K & R & G & T & V & A & D & N & D & S & R & V & R & A\end{array}$ TACAAGCCAATCATCGCAGGAAGCTGGAAGgATGGAAGTCGgTAAGgAGgAaCATCTACGAGAGAGTTTT $\begin{array}{lllllllllllllllllllllll}T & S & Q & S & S & Q & E & A & G & R & M & E & V & G & K & E & E & H & I & R & E & S & F\end{array}$ TCATCTTCCGAGCTTCTGAAGGGCAAGAACGACCCCAACGCTGTGGCCGGAGCCGTCGGTTTCAGCGTTA $\begin{array}{llllllllllllllllllllllll}\mathbf{S} & \mathbf{S} & \mathbf{S} & \mathbf{E} & \text { I } & \text { L } & \text { K } & G & \text { K } & \text { N } & \text { D } & \text { P } & \text { N } & \text { A } & \text { V } & \text { A } & G & \text { A } & \text { V } & G & \text { G } & S & \text { V } & R\end{array}$ GAGAGCCCAAGTTCTACGTGTTCAAGGCGAAAGCCGTCATTCTGGCAACCGGAGGTGCAACACTGCTCTT $\begin{array}{lllllllllllllllllllllll}\text { E } & \text { P } & \text { K } & \text { F } & \text { Y } & \text { V } & \text { F } & \text { K } & \text { A } & \text { K } & \text { A } & \text { V } & \text { I } & \text { L } & \text { A } & \text { T } & G & G & \text { A } & \text { T } & \text { L } & \text { L } & \text { F }\end{array}$ CAGGCCGAGAAGCACTGGCGAAGCAGCAGgAAGgACATGGTATGCAATCTTCGACACTGGCAGCGGTTAC $\begin{array}{lllllllllllllllllllllll}\mathbf{R} & \mathbf{P} & \mathbf{R} & \mathbf{S} & \mathbf{T} & \mathbf{G} & \mathbf{E} & \mathbf{A} & \mathbf{A} & \mathbf{G} & \mathbf{R} & \mathbf{T} & \mathbf{W} & \mathbf{Y} & \mathbf{A} & \mathbf{I} & \mathbf{F} & \mathbf{D} & \mathbf{T} & \mathbf{G} & \mathbf{S} & \mathbf{G} & \mathbf{Y}\end{array}$ TACATGGGCTTGAAGGCCGGAGCGATGCTCACGCAGTTTGAACACCGCTTCATACCCTTCAGGTTCAAGG

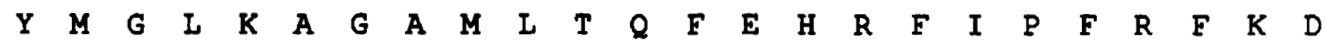
ACGGTTACGGCCCAGTTGGAGCATGGTTCCTGTTCTTCAAGTGTAAGGCCAAGAACGCGTATGGAGAGGA $\begin{array}{lllllllllllllllllllllll}G & Y & G & P & V & G & A & W & F & L & F & F & K & C & K & A & K & N & A & Y & G & E & E\end{array}$ GTACATCAAGACAAGGGCTGCAGAGCTTGAGAAGTACAAGCCCTACGGTGCAGCCCAGCCAATCCCGACA

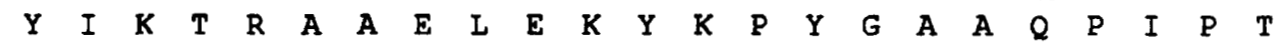

Fig. 2. For legend see facing page. 
1490 CCGCTGAGAAACCACCAGGTCATGCTCGAAATCATGGACGGCAACCAGCCAATCTACATGCACACTGAGA

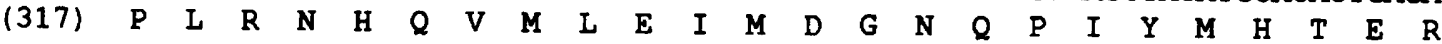

1560 GGCTTCTCGCTGAGCTGGCTGGAGGAGACAAGAAGAAGCTGAAGCACATCTACGAGGAGGCTTTCGAGGA

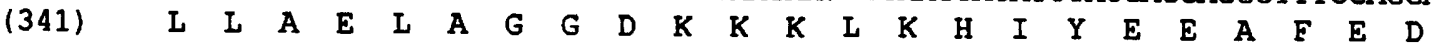

1630 CTTCCTCGACATGACAGTCAGCCAGGCTCTGCTGTGGGCCTGCCAGAACATCGACCCGCAGGAGCAGCCG

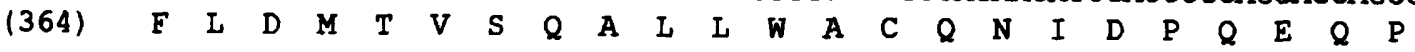

1700 TCTGAAGCTGCACCGGCTGAGCCCTACATCATGGGTTCACACAGCGGTGAGGCAGGTTTCTGGGTATGCG

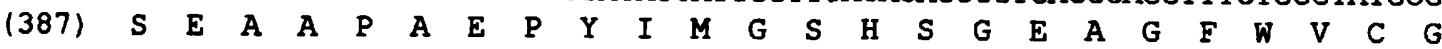

1770 GTCCTGAGGATCTGATGCCGGAGGAGTACGCAAAGCTCTTCCCGCTGAAGTACAACAGGATGACCACAGT $\begin{array}{llllllllllllllllllllllll}\text { (411) } & \text { P } & \text { E } & \text { D } & \text { L } & M & \text { P } & \text { E } & \text { E } & \text { Y } & \text { A } & \text { K } & \text { L } & \text { F } & \text { P } & \text { L } & \text { K } & \text { Y } & \text { N } & \text { R } & \text { M } & \text { T } & T & \text { V }\end{array}$

1840 CAAGGGACTCTTCGCCATCGGTGACTGTGCTGGTGCCAACCCGCACAAGTTCTCCAGGGTTCGTTCACTG $\begin{array}{lllllllllllllllllllllllll}\text { (434) } & \text { K } & G & \text { L } & \text { F } & \text { A } & \text { I } & G & \text { D } & \text { C } & \text { A } & G & \text { A } & \text { N } & \text { P } & \text { H } & \text { K } & \text { F } & \text { S } & \text { R } & \text { V } & R & S & \text { L }\end{array}$

1910 AGGCAGGATTGTAGCGAAGGCGCAGTGATGTTCATCCCCGAGCAGAAGCCCAACCCAGAAATTGACGATG

$\begin{array}{llllllllllllllllllllllllll}\text { (457) } & R & Q & D & C & S & E & G & A & V & M & F & I & P & E & Q & K & P & N & P & E & I & D & D & A\end{array}$

1980 CGGTCGTTGAGGAACTCAAGAAGAAGGCCTACGCACCGATGGAGAGGTTCATGCAGTACAAGGACCTCTC

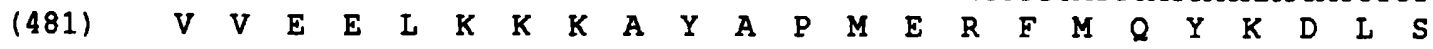

2050 AACTGCCGATGACGTCAACCCAGAGTACATCCTGCCGTGGCAGGGTCTTGTCAGGCTGCAGAAGATCATG

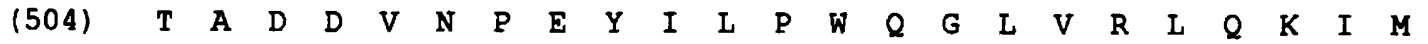

2120 GACGAGTATGCTGCTGGAATTGCAACAATCTACAAGACCAACGAGAAGATGCTGCAGAGAGCTCTTGAGC $\begin{array}{lllllllllllllllllllllllll}\text { (527) } & D & E & Y & A & A & G & I & A & T & I & Y & K & T & N & E & K & M & L & Q & R & A & L & E & L\end{array}$ 2190 TGCTCGCCTTCCTGAAGGAGGACCTCGAGAAGCTCGCTGCAAGAGACCTCCACGAGCTGATGAGAGCATG (551) I

2260 GGAGCTTGTCCACAGAGTCTGGACTGCTGAGGCACACGTCAGGCACATGCTCTTCAGAAAGGAAACCAGA $\begin{array}{llllllllllllllllllllllll}\text { (574) } & \text { E } & \text { L } & \text { V } & \text { H } & \text { R } & \text { V } & \text { W } & \text { T } & \text { A } & \text { E } & \text { A } & \text { H } & \text { V } & \text { R } & \text { H } & \text { M } & \text { L } & \text { F } & \text { R } & \text { K } & \text { E } & \text { T } & R\end{array}$

2330 TGGCCCGGATACTACTACAGAACCGACTACCCAGAGCTCAACGACGAGGAGTGGAAGTGCTTCGTCTGCA (597) W 2400 GCAAGTACGACGCTGAGAAGGACGAGTGGACCTTCGAGAAAGTGCCGTACGTGCAGGTCATCGAGTGGAG $\begin{array}{llllllllllllllllllllllll}\text { (621) } & \text { K } & \text { Y } & \text { D } & \text { A } & \text { E } & \text { K } & \text { D } & \text { E } & \text { W } & \text { T } & \text { F } & \text { E } & \text { K } & \text { V } & \text { P } & \text { Y } & \text { V } & \text { Q } & \text { V } & \text { I } & \text { E } & \text { W } & S\end{array}$

2470 CTTCTAAAGCTCTAAAATTrTTCTTTrTTCTAAATCTAAAAGTTTTTATTGCATTGGCTTAACTCTGCAT

(644) F END tx term

2540 CATGTACTTGGAACCCTGCCATTGAGAGGCTAAATGCCAAGGAGCTTGAGGAGAATACAGGAGCGCAAGC

2670 TCAAGGCCTGGGTAAGCACAAGTCTATCAAGTATTCCCCCCTTCTTTCGCCAGAGGGTTCAAGGAGGCTG

2680 GAGTAACAACTGACGACATCAAAAGTCTGAACGATTGGCCC

Fig. 2. Nucleotide sequence of the $A$. fulgidus apr locus. Deduced amino acid sequences for two open reading frames, designated aprB and aprA, are shown below the sequence. Nucleotides are numbered beginning at the first position of the sequence and amino acid positions are shown in parentheses. The following features are indicated: Hindlll sites; $t x$ term, putative transcription termination signal; rbs, putative ribosome binding sites. The underlined amino acid sequences correspond to the amino-terminal peptide sequences that were chemically determined from purified APS reductase.

addition to $a p r B$ (residues 73-525) an ORF of $1935 \mathrm{bp}$ (apr $A$ ) spanning residues $542-2476$ was identified which encodes a 644 residue, $73.3 \mathrm{kDa}$ peptide. The lack of an amino-terminal methionine in both mature peptides indicates that it is removed during post-translational processing. The molecular masses deduced for the apr $A$ and $a p r B$ encoded peptides are in good agreement with the values obtained for the $\alpha$ and $\beta$ subunits by SDSPAGE analysis. A molecular mass of $163700 \mathrm{Da}$ can be calculated for an $\alpha_{2} \beta$-structured APS reductase, which is in close agreement with the value obtained by gel filtration (Speich \& Trüper, 1988).
The $54.2 \% \mathrm{G}+\mathrm{C}$ content of the $a \operatorname{pr} B A$ region is higher than the value of $46 \%$ found for $A$. fulgidus total DNA (Stetter et al., 1987). The codon usage of $\operatorname{aprB} A$, with preference for $\mathrm{G}$ and $\mathrm{C}$ in the third base position, is similar to that in the $d s r A B$ genes (Dahl et al., 1993).

As shown in Fig. 2 each of the two ATG initiation codons is preceded by a putative ribosome-binding site (RBS), at least 6 nucleotides of which are complementary to 9 nucleotides at the $3^{\prime}$-end of the $16 \mathrm{~S}$ rRNA of $A$. fulgidus (UCCUCCACU; Achenbach-Richter et al., 1987). The high degree of complementarity of the RBS to the $3^{\prime}$ - 


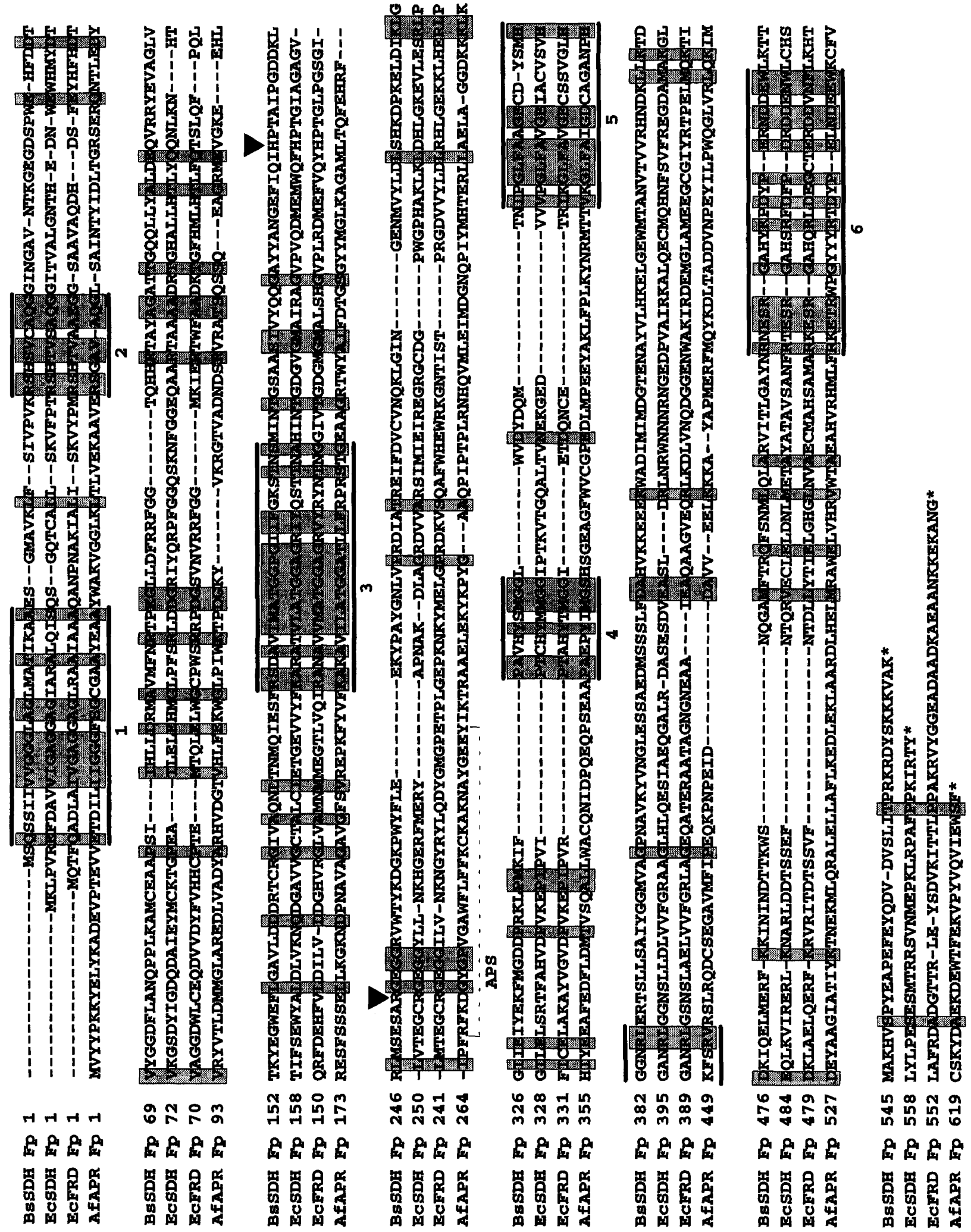

Fig. 3. For legend see facing page. 
terminus of $16 \mathrm{~S}$ rRNA may reflect the capacity of the cell to express the APS reductase genes at a high level, since this enzyme accounts for more than $2 \%$ of the total cellular soluble protein when the organism is grown on sulphate (Speich \& Trüper, 1988). Comparable to $d s r A$ and $d s r B$ from $A$. fulgidus, the strong preference for $C$ in codons of the type NNC/T observed in aprB $A$ may also favour efficient translation, as has been proposed for the mor genes of Methanococcus vannielii (Cram et al., 1987).

A sequence perfectly reresenting the 2 -fold repetition of a conserved heptanucleotide (TTTTTYT), which has been proposed to be a transcription termination signal in extremely thermophilic sulphur-dependent archaea (Reiter et al., 1988), is located 11 nucleotides downstream of the TAA stop codon of $\operatorname{apr} A$. Neither $a \operatorname{pr} A$ nor $a p r B$ are preceded by sequences showing significant homology to consensus promoters proposed for archaea (Brown et al., 1989), indicating that these two genes are probably part of a larger transcriptional unit. We consider it to be a likely possibility that the APS reductase genes form an operon with those encoding ATP sulphurylase. This enzyme catalyses sulphate activation to adenylylsulphate which then serves as the substrate of APS reductase. The genes encoding dissimilatory sulphite reductase ( $d s r A$ and $d s r B)$, which catalyses the final step of the sulphate reduction pathway, form a separate transcriptional unit (Dahl $e t$ al., 1993). This could enable the cell to transcribe $d s r A B$ independently from $a \operatorname{pr} B A$ and the genes for ATP sulphurylase and to express these genes differentially under different growth conditions.

\section{Peptides encoded by aprA and aprB}

Unlike terminal oxidases in aerobic respiration, the reductases of the sulphate-reducing prokaryotes including A. fulgidus are soluble enzymes that are not tightly associated with the cytoplasmic membrane (LeGall \& Fauque, 1988; Speich \& Trüper, 1988). Growth of these organisms on lactate and sulphate, however, requires that at least part of the reducing power be transferred from the membrane-localized electron-transport chain to APS reductase, and it has been suggested that menaquinone serves as the electron donor of APS-reductase-catalysed adenylylsulphate reduction (Kunow \& Thauer, 1993). A hydropathy analysis profile (Kyte \& Doolittle, 1982) of the peptides encoded by $\operatorname{apr} A$ and $\operatorname{apr} B$ (not shown) did not reveal markedly hydrophobic segments that would be likely to mediate membrane integration. This does not, however, exclude reaction of the soluble APS reductase with membrane-bound electron carriers, as has been discussed for dissimilatory sulphite reductase from the same organism (Dahl et al., 1993).

Amino acid sequence data has been obtained for only one other APS reductase. Comparison with the chemically determined amino acid sequence of the $\alpha$ subunit of Thermodesulfobacterium commune APS reductase (M. Walbröl, personal communication) showed identities at 7 of 24 amino acids sequenced, indicating that these two peptides are homologous (not shown).

Comparison of the apr $A$ encoded peptide to the sequences in the Swiss-Prot Data Base using the program FASTA revealed significant homology with the flavoprotein subunits of several bacterial and eukaryotic FAD-containing reductases and dehydrogenases. Fig. 3 shows an alignment of the amino acid sequence deduced from $a p r A$ with those of the flavoprotein subunits of fumarate dehydrogenase (FRD) from E. coli (Cole, 1982) and the succinate dehydrogenase (SDH) from Bacillus subtilis (Phillips et al., 1987) and E. coli (Wood et al., 1984). The overall similarity between the archaeal and the bacterial flavopeptides varies between 29 and $30 \%$ when matches between similar amino acids are included (after Dayhoff $e t$ al., 1978); the percentage of identical amino acids is 15 to $17 \%$.

The alignment of the four peptides reveals that the conserved regions are not statistically distributed but are concentrated in six segments (marked by lines and numbered in Fig. 3). Four of these segments can be assigned to domains that are involved in binding the FAD prosthetic group: Segment 1 at the amino-terminal end of the flavoproteins corresponds to part of a consensus sequence for ADP binding sites derived by Wierenga et al. (1986). More specifically, the sequences compared here match a fingerprint proposed to be diagnostic for amino acid sequences that form a $\beta \alpha \beta$-fold with binding properties for the ADP moiety of FAD or NAD(P). While the length of the consensus sequence is not constant due to length variability of a loop between the $\alpha$-helix and the second $\beta$-strand, 11 positions have been defined for which certain amino acids are required as structure-forming residues. Three glycine residues at positions 6,8 and 11 , and an acidic residue at the end of the fingerprint are especially important and therefore designated as 'core'fingerprint (Wierenga et al., 1986). As shown in Fig. 4, residues 24-56 of the deduced APS reductase sequence match the fingerprint including the core residues at 10 positions and therefore most probably serve as the binding site for the ADP portion of FAD. In analogy with the

Fig. 3. Alignment of the deduced amino acid sequence of aprA from $A$. fulgidus with those of the flavoprotein (Fp) subunits of three bacterial dehydrogenases. Amino acid positions are indicated. The abbreviations are: BsSDH, Bacillus subtilis succinate dehydrogenase (Phillips et al., 1987); EcSDH, E. coli succinate dehydrogenase (Wood et al., 1984); EcFRD, $E$. coli fumarate dehydrogenase (Cole, 1982); AfAPR, A. fulgidus aprA-encoded peptide. The proposed APS binding site is indicated. Arrows show the potential active site histidine and arginine residues in SDH and FRD. Shaded boxes indicate positions at which similar or identical amino acids are present in all four sequences. For this comparison the following are considered similar: aspartate, glutamate, asparagine and glutamine (D, E, N and $Q)$; arginine, histidine and lysine ( $R, H$ and $K)$; isoleucine, valine, methionine and leucine (I, V, M and $L$ ); phenylalanine, tyrosine and tryptophan $(F, Y$ and $W)$; serine, threonine, proline, alanine and glycine (S, T, P, A and G) (Dayhoff et al., 1978). Segments of particularly high homology are numbered and highlighted by lines. 
Secondary

structure

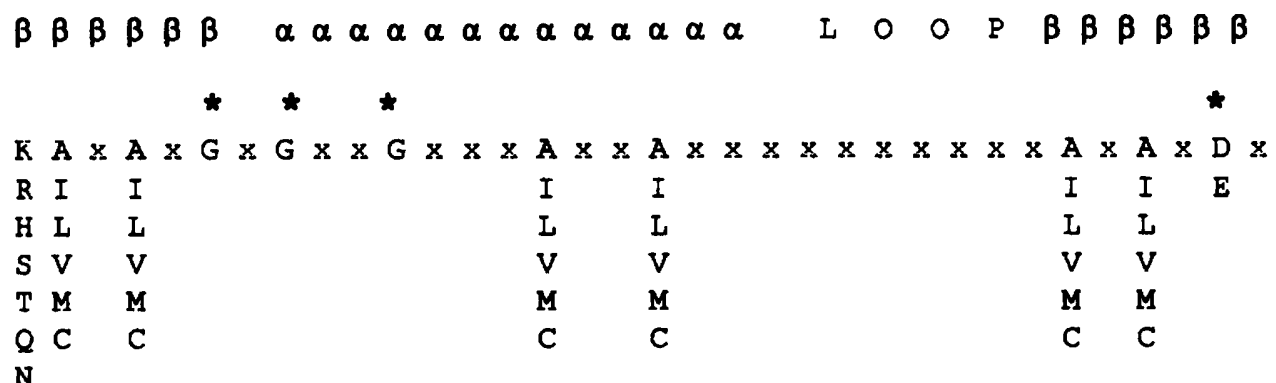

Amino acid

fingerprint

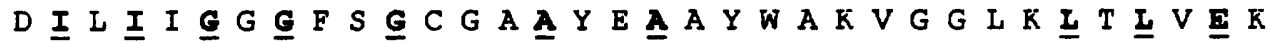

AfAPR Fp 24-56

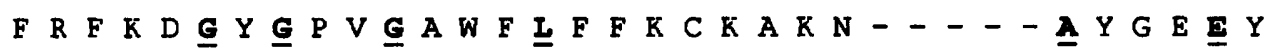

AfAPR Fp 265-292

Fig. 4. Potential ADP binding folds in the deduced amino acid sequence of aprA. The sequences were aligned with a fingerprint sequence that folds into a $\beta \alpha \beta$-structure with ADP binding properties (Wierenga et al., 1986). Amino acids which match the fingerprint are underlined. Positions of the 'core' fingerprint are marked by asterisks.

three-dimensional structure of human glutathione reductase (Guest \& Rice, 1984; Rice et al., 1984) the GGGturn found at position 30-32 of the $\operatorname{apr} A$ deduced sequence is in close contact with the pyrophosphate group of the FAD.

The ADP-binding domain is immediately followed by another segment (2) of particularly high sequence conservation. In all but the apr $A$-encoded peptide a conserved histidine residue is found in this region. This residue has been shown to be involved in covalent linkage of the flavin portion of the FAD cofactor (Kenney et al., 1972; Cole, 1982; Wood et al., 1984; Phillips et al., 1987). The conserved histidine has been replaced by cysteine, serine, arginine or tyrosine via site-directed mutagenesis in E. coli fumarate reductase resulting in an enzyme retaining activity but containing an FAD molecule which is non-covalently bound to the enzyme (Blaut et al., 1989). Equivalent substitutions in D-nicotinic acid oxidase from Arthrobacter oxidans also resulted in loss of covalent attachment of the FAD (Mauch et al., 1989). In the peptide deduced from $\operatorname{apr} A$ the conserved histidine is replaced by a glycine residue, indicating that the FAD prosthetic group is not covalently bound in the archaeal APS reductase. Indeed, previous results clearly showed that the flavin moiety is not covalently linked to the enzyme (Speich \& Trüper, 1988).

Another example of a flavoprotein related to fumarate reductases and succinate dehydrogenases but containing non-covalently bound FAD is the soluble flavocytochrome $c$ of Shewanella putrefaciens (Pealing et al., 1992). A round the flavin attachment site the amino acid sequence of this protein is, however, not related to the enzymes with covalently bound flavin. The archaeal APS reductase, therefore, appears to be the first enzyme with noncovalently bound FAD that lacks the conserved histidine residue but contains a region homologous to the FAD attachment site in fumarate reductases and succinate dehydrogenases. Implications of our finding on the evolution of covalent binding of FAD will have to be discussed in the future when more APS reductase

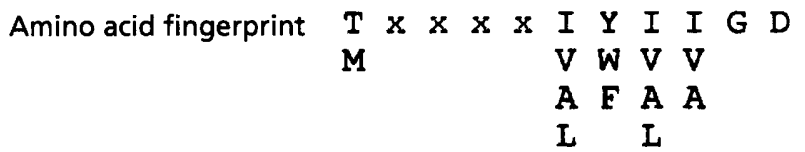

AfAPR Fp 431-441 $\underline{\underline{T}}$ T $V$ K G I $\underline{\mathbf{I}} \underline{\mathbf{A}} \underline{\mathbf{I}} \underline{\mathbf{G}} \underline{\mathbf{D}}$

Fig. 5. Potential binding site of the ribityl chain of FAD in the deduced amino acid sequence of aprA. The sequence is aligned with a fingerprint proposed by Eggink et al. (1990). Amino acids which match the fingerprint are underlined.

sequences are available for comparative studies. As pointed out by Hederstedt (1987), the primary sequence around the histidine is not conserved in all proteins with histidine-bound FAD. This suggests that the conserved sequence is more important for enzyme function than for binding of the flavin.

The sequence at positions 394 to 453 of the apr $A$-encoded peptide, which comprises two highly conserved segments (4 and 5), is homologous to an amino acid sequence in human glutathione reductase forming part of the FAD binding pocket (Cole et al., 1985). Segment 5 contains a stretch of amino acids matching a fingerprint that has been proposed to be indicative of sites which bind the ribityl chain of the flavin moiety (Eggink et al., 1990). Fig. 5 shows an alignment of the apr $A$-deduced peptide with this fingerprint. Studies on the three-dimensional structure of $p$-hydroxybenzoate hydroxylase from Pseudomonas fuorescens (Schreuder et al., 1988), human glutathione reductase (Karplus \& Schulz, 1987) and lipoamide dehydrogenase from Azotobacter vinelandii (Schierbeek et al., 1989) revealed that the conserved Asp at the end of the fingerprint forms hydrogen bonds with the O-3 group of the ribityl chain of the flavin moiety. It is therefore likely that Asp-441 has the same function in APS reductase.

Quantitative measurements showed the presence of only 1 mol FAD per mol of $A$. fulgidus APS reductase holoenzyme composed of one $\beta$ and two flavoprotein subunits 


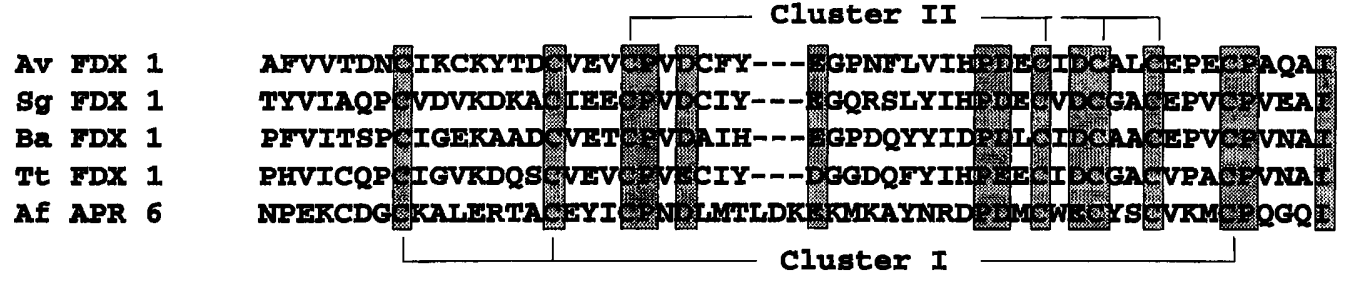

Fig. 6. Alignment of the cysteine clusters predicted by aprB to those of 7-Fe ferredoxins (Fdx). Sequences of subunits of the following enzymes and ferredoxins are aligned: Av, Azotobacter vinelandii (Stout, 1988); Tt, Thermus thermophilus (Sato et al., 1981); Sg, Streptomyces griseus (Trower et al., 1990); Ba, Bacillus acidocaldarius (Schlatter et al., 1985); Af APR, A. fulgidus APS reductase. Cysteine ligating clusters I and II, respectively, are indicated (after lismaa et al., 1991). Shaded boxes indicate positions at which similar or identical amino acids are present in all four sequences. Amino acid similarity groups cf. Fig. 3.

(Speich \& Trüper, 1988). Since some flavin loss may have occurred during enzyme preparation we cannot fully exclude that the native archaeal APS reductase carries one FAD prosthetic group per $\alpha$ subunit. It should, however, be taken into consideration that all other APS reductases studied so far have independently been reported to contain either one FAD per enzyme molecule or one FAD per eight iron atoms (cf. the review by Fauque et al., 1991). Exactly the same stoichiometries are observed for the $A$. fulgidus enzyme. We therefore want to point out the possibility that the FAD binding site present in each of the two $\alpha$ subunits might represent a form of 'half of sites reactivity' comparable to the flavoprotein of assimilatory sulphite reductase from $E$. coli where binding sites for FAD as well as for FMN are proposed to function in a similar manner (Ostrowski et al., 1989). In addition to the binding sites of the FAD cofactor there are two more highly conserved segments ( 3 and 6 ) with as yet unknown function.

APS reductases from dissimilatory sulphate reducers have been reported to be inhibited by sulphydryl reagents (Peck et al., 1965; Stille \& Trüper, 1984), indicating that thiol groups may be essential for catalysis. None of the eight cysteine residues in the $\operatorname{apr} A$-deduced sequence is strictly conserved in all four flavoproteins compared in Fig. 2 and only one of them (Cys-442) occupies a comparable position in E. coli FRD and B. subtilis SDH. This residue is, however, not conserved in most other succinate dehydrogenases and fumarate reductases (Pealing et al., 1992) and identification of potentially essential cysteines will have to await sequencing of further APS reductases. The only strictly conserved histidine residue (His-448 in the apr $A$-deduced sequence) has been suggested to be catalytically important and may perform a proton donor-acceptor function during catalysis. This residue is probably located close to the isoalloxazine ring of the FAD prosthetic group (Vik \& Hafeti, 1981; Hederstedt \& Hafeti, 1986; Hederstedt, 1987).

In the region between residues 255 and 330 APS reductase shows little homology to bacterial SDH and FRD. An active site histidine and a substrate-binding arginine residue (H-232 and $\mathrm{R}-248$ of E. coli fumarate reductase) are localized in the corresponding regions of SDH and FRD, indicating that this portion of the polypeptides is responsible for substrate binding and specificity (Schröder et al., 1991). With respect to the different metabolic functions of the enzymes in comparison one has to expect a different sequence in the corresponding region of APS reductase. Indeed, we found a second region resembling an ADP binding site in this part of the sequence. This stretch of amino acids (residues 265-292) perfectly fits the 'core' fingerprint proposed by Wierenga et al. (1986) and matches the whole fingerprint at six of eleven positions (Fig. 4). The three-dimensional structure of this region may therefore resemble the typical ADP-binding $\beta \alpha \beta$ fold. Since the substrate of APS reductase, adenosine- $5^{\prime}$ phosphosulphate, is structurally very similar to ADP this part of the enzyme could represent at least part of the substrate binding site. Other proteins with two nucleotide binding sites are oxidoreductases that besides FAD bind NAD or NADP. Comparable to the second site in those proteins the APS binding site proposed by us is located approximately in the middle of the apr $A$-encoded sequence.

Previous results have demonstrated the presence of eight non-haem iron and six acid-labile sulphur atoms within A. fulgidus APS reductase (Speich \& Trüper, 1988). The peptide encoded by $a p r B$ contains nine cysteine residues, eight of which occur in two clusters. The spacing of these cysteine residues resembles that of $7-\mathrm{Fe}$ ferredoxins (Fig. 6), including the ferredoxin from Azotobacter vinelandii which is known from $\mathrm{X}$-ray studies to contain an $\left[\mathrm{Fe}_{3} \mathrm{~S}_{4}\right]$ and an $\left[\mathrm{Fe}_{4} \mathrm{~S}_{4}\right]$ centre (Stout, 1988). Similarities between this ferredoxin and $A$. fulgidus APS reductase extend to electrochemical properties: both contain one ironsulphur cluster easily reducible by dithionite (Cluster I) and an $\left[\mathrm{Fe}_{4} \mathrm{~S}_{4}\right]$ centre (Cluster II) which only partially reacts with this reductant at higher $\mathrm{pH}$ (Lampreia et al., 1991; Iismaa et al., 1991). It is interesting to note in this regard that oxidized APS reductase shows electron paramagnetic resonance (EPR) spectra of a minor paramagnetic species reminiscent of $\left[\mathrm{Fe}_{3} \mathrm{~S}_{4}\right]$ clusters (Lampreia et al., 1991). However, the main species of clusters in the reduced state in $A$. fulgidus APS reductase show EPR spectra clearly identifying them as $\left[\mathrm{Fe}_{4} \mathrm{~S}_{4}\right]$ centres. Interconversion of $\left[\mathrm{Fe}_{3} \mathrm{~S}_{4}\right]$ to $\left[\mathrm{Fe}_{4} \mathrm{~S}_{4}\right]$ clusters in proteins purified aerobically as was the case for APS reductase have repeatedly been described and the question whether 
$\left[\mathrm{Fe}_{3} \mathrm{~S}_{4}\right]$ clusters are due to oxidative damage or indeed do have biological meaning has not been settled (Bruschi \& Guerlesquin, 1988; George et al., 1989). Analogous to $A$. vinelandii ferredoxin, cysteines 13,21 and 51 of the aprBencoded peptide probably ligate cluster I which corresponds to the $\left[\mathrm{Fe}_{3} \mathrm{~S}_{4}\right]$ centre in the $A$. vinelandii protein, whereas Cys-25, Cys-47, Cys-50 and Cys-53 bind cluster II. If APS reductase contains two $\left[\mathrm{Fe}_{4} \mathrm{~S}_{4}\right]$ clusters in vivo each of these requires four ligands. The aprB-encoded peptide contains an additional cysteine at position 10 which could serve as a fourth thiolate ligand for a $\left[\mathrm{Fe}_{4} \mathrm{~S}_{4}\right]$ structured cluster I. It has, however, been proposed that the corresponding residue in Thermus thermophilus ferredoxin is extraneous and not involved in binding of an iron-sulphur cluster (George et al., 1985). Alternatively, cluster I of the aprB-encoded peptide could include a non-cysteine ligand in its coordination, possibly water or hydroxyl from solvent as has been shown for activated pig heart aconitase (Robbins \& Stout, 1989).

A notable difference between the sequence deduced from $a p r B$ and the Bacillus acidocaldarius ferredoxin sequence and those of the other 7-Fe ferredoxins shown in Fig. 6 is the absence of an otherwise strictly conserved cysteine residue (Cys-24 in the $A$. vinelandii sequence). In the $A$. vinelandii protein this residue is in Van der Waals contact with cluster II (Stout, 1988). By site directed mutagenesis it was shown, however, that it is neither essential for assembly of a functional $\left[\mathrm{Fe}_{4} \mathrm{~S}_{4}\right]$-structured cluster II nor required for liganding cluster I (Iismaa et al., 1991).

\section{Concluding remarks}

The genes encoding the two different subunits of APS reductase from the extremely thermophilic archaeon $A$. fulgidus were isolated and the DNA sequence determined. This appears to be the first reported characterization of APS reductase genes. The sequence data obtained classified the archaeal APS reductase as a typical iron-sulphur flavoprotein with significant homology to its bacterial counterparts and allowed identification of probable substrate and cofactor binding sites. In the future, comparative amino acid sequence analyses should not only provide estimates of the evolutionary divergence of APS reductases and information about the evolution of sulphur metabolism in general but also about the evolution of FAD and iron-sulphur cluster binding sites.

\section{ACKNOWLEDGEMENTS}

We thank Dirk Allmeroth for help with sequencing. This work was supported by the Fonds der Chemischen Industrie and by grant $\operatorname{Tr} 133 / 20-1$ from the Deutsche Forschungsgemeinschaft.

\section{REFERENCES}

Achenbach-Richter, L., Stetter, K. O. \& Woese, C. R. (1987). A possible biochemical missing link among archaebacteria. Nature 327, 348-349.

Beijerinck, M. W. (1895). Über Spirillum desulfuricans als Ursache von Sulfatreduktion. Centralblatt Bakteriol II, Abteil 1, 1-9.

Blaut, M., Whittaker, K., Valdovinos, A., Ackrell, B. A. C., Gun- salus, R. P. \& Cecchini, G. (1989). Fumarate reductase mutants of Escherichia coli that lack covalently bound flavin. $J$ Biol Chem 264, 13599-13604.

Bramlett, R. N. \& Peck, H. D., Jr (1975). Some physical and kinetic properties of adenylyl sulfate reductase from Desulfovibrio vulgaris. J Biol Chem 250, 2979-2986.

Brown, J. W., Daniels, C. J. \& Reeve, J. N. (1989). Gene structure, organization, and expression in archaebacteria. Crit Rev Microbiol 16, 287-338.

Bruschi, M. \& Guerlesquin, F. (1988). Structure, function and evolution of bacterial ferredoxins. FEMS Microbiol Rev 54, 155-176.

Cole, S. T. (1982). Nucleotide sequence coding for the flavoprotein subunit of the fumarate reductase of Escherichia coli. Eur J Biochem 122, 479-484.

Cole, S. T., Codon, C., Lemire, B. D. \& Weiner, J. H. (1985). Molecular biology, biochemistry and bioenergetics of fumarate reductase, a complex membrane-bound iron-sulfur flavoenzyme of Escherichia coli. Biochim Biophys Acta 811, 381-403.

Cram, D. S., Sherf, A., Libby, R. T., Mattaliano, R. J., Ramachandran, K. L. \& Reeve, J. N. (1987). Structure and expression of the genes, $\operatorname{mcr} B D C G A$, which encode the subunits of component $C$ of methyl coenzyme $\mathrm{M}$ reductase in Methanococcus vannielii. Proc Natl Acad Sci US A 84, 3992-3996.

Dahl, C., Koch, H. G., Keuken, O. \& Trüper, H. G. (1990). Purification and characterization of ATP sulfurylase from the extremely thermophilic archaebacterial sulfate-reducer, Archaeoglobus fulgidus. FEMS Microbiol Lett 67, 27-32.

Dahl, C., Kredich, N. M., Deutzmann, R. \& Trüper, H. G. (1993). Dissimilatory sulphite reductase from Archaeoglobus fulgidus: physicochemical properties of the enzyme and cloning, sequencing and analysis of the reductase genes. J Gen Microbiol 139, 1817-1828.

Dayhoff, M. O., Schwartz, R. M. \& Orcutt, B. C. (1978). A model of evolutionary change in proteins. In Atlas of Protein Sequence and Structure, vol. 5, suppl. 3, pp. 345-352. Edited by M. O. Dayhoff. Washington, DC: National Biomedical Research Foundation.

Devereux, J., Haeberli, P. \& Smithies, O. (1984). A comprehensive set of sequence analysis programs for the VAX. Nucleic Acids Res 12, 387-395.

Eggink, G., Engel, H., Vriend, G., Terpstra, P. \& Witholt, B. (1990). Rubredoxin reductase of Pseudomonas oleovorans. Structural relationship to other flavoprotein oxidoreductases based on one NAD and two FAD fingerprints. $J$ Mol Biol 212, 135-142.

Fauque, G., Czechowski, M. H., Kang-Lissolo, L., DerVartanian, D. V., Moura, J. J. G., Moura, I., Lampreia, J., Xavier, A. V. \& LeGall, J. (1986). Purification of adenylyl sulfate (APS) reductase and desulfofuscidin from a thermophilic sulfate reducer: Desulfovibrio thermophilus. Abstracts of the Annual Meeting of the Society for Industrial Microbiology, San Francisco, p. 92.

Fauque, G., LeGall, J. \& Barton, L. L. (1991). Sulfate-reducing and sulfur-reducing bacteria. In Variations in Autotrophic Life, pp. 271-337. Edited by J. M. Shively \& L. L. Barton. New York: Academic Press.

Feinberg, A. P. \& Vogelstein, B. (1983). A technique for radiolabeling DNA restriction endonuclease fragments to high specific activity. Anal Biochem 132, 6-13.

George, D. H., Hunt, L. T., Yeh, L. S. L. \& Barker, W. C. (1985), New perspectives on bacterial ferredoxin evolution. $J \mathrm{Mol}$ Evol 22, 20-31.

George, S. J., Armstrong, F. A., Hatchikian, E. C. \& Thomson, A. J. (1989). Electrochemical and spectroscopic characterization of the conversion of the $7 \mathrm{Fe}$ into the $8 \mathrm{Fe}$ form of ferredoxin III from Desulfovibrio africanus. Biochem J 264, 275-284. 
Guest, J. R. \& Rice, D. W. (1984). Molecular genetic approaches to the study of E. coli flavoproteins. In Flavins and Flavoproteins, pp. 111-124. Edited by R. C. Bray, P. C. Engel \& S. G. Mayhew. Berlin: Walter de Gruyter.

Hederstedt, L. (1987). Covalent binding of FAD to Bacillus subtilis succinate dehydrogenase. In Flavins and Flavoproteins, pp. 729-735. Edited by D. E. Edmondson \& D. B. McCormick. Berlin: Walter de Gruyter.

Hederstedt, L. \& Hafeti, Y. (1986). Modification of bovine heart succinate dehydrogenase with ethoxyformic anhydride and rose bengal: evidence for essential histidyl residues protectable by substrates. Arch Biochem Biophys 247, 346-354.

lismaa, S. E., Vázquez, A. E., Jensen, G. M., Stephens, P. J., Butt, J. N., Armstrong, F. A. \& Burgess, B. K. (1991). Site-directed mutagenesis of Azotobacter vinelandii ferredoxin. $J$ Biol Chem 266, 21563-21571.

Karplus, P. A. \& Schulz, G. E. (1987). Refined structure of glutathione reductase at $1.54 \AA$ resolution. $J$ Mol Biol 195, 701-729.

Kenney, W. C., Walker, W. H. \& Singer, T. P. (1972). Studies on succinate dehydrogenase. J Biol Chem 247, 4510-4513.

Kremer, D. R., Venhuis, M., Fauque, G., Peck, H. D., Jr, LeGall, J., Lampreia, J., Moura, J. J. G. \& Hansen, T. A. (1988). Immunocytochemical localization of APS reductase and bisulfite reductase in three Desulfovibrio species. Arch Microbiol 150, 296-301.

Kunow, J. \& Thauer, R. K. (1994). Sulfate reducing Archaea. In Biotechnology Handbooks: Sulfate-reducing Bacteria. Edited by L. L. Barton. New York: Plenum Publishing Corp. (in press).

Kyte, J. \& Doolittle, R. F. (1982). A simple method for displaying the hydropathic character of a protein. J Mol Biol 157, 105-132.

Laemmli, U. K. (1970). Cleavage of structural proteins during the assembly of the head of bacteriophage T4. Nature 227, 680-685.

Lampreia, J., Moura, I., Teixeira, M., Peck, H. D., Jr, LeGall, J., Huynh, B. \& Moura, J. J. G. (1990). The active centers of adenylylsulfate reductase from Desulfovibrio gigas. Characterization and spectroscopic studies. Eur J Biochem 188, 653-664.

Lampreia, J., Fauque, G, Speich, N., Dahl, C., Moura, I., Trüper, H. G. \& Moura, J. J. G. (1991). Spectroscopic studies on APS reductase from the hyperthermophilic sulfate-reducing archaebacterium Archaeoglobus fulgidus. Biochem Biopbys Res Commun 181, 342-347.

LeGall, J. \& Fauque, G. (1988). Dissimilatory reduction of sulfur compounds. In Biology of Anaerobic Microorganisms, pp. 587-639. Edited by A. J. B. Zehnder. New York: J. Wiley \& Sons.

Mauch, L., Bichler, V. \& Brandsch, R. (1989). Site-directed mutagenesis of the FAD-binding histidine of 6-hydroxy-D-nicotine oxidase. FEBS Lett 257, 86-88.

Ostrowski, J., Barber, M. J., Rueger, D. C., Miller, B. E., Siegel, L. M. \& Kredich, N. M. (1989). Characterization of the flavoprotein moieties of NADPH-sulfite reductase from Salmonella typhimurium and Escherichia coli: physicochemical and catalytic properties, amino acid sequence deduced from the DNA sequence of $c y^{s} J$ and comparison with NADPH-cytochrome P-450 reductase. $J$ Biol Chem 264, 15796-15808.

Pealing, S. L., Black, A. C., Manson, F. D. C., Ward, F. B., Chapman, S. K. \& Reid, G. A. (1992). Sequence of the gene encoding flavocytochrome $c$ from Shewanella putrefaciens: a tetraheme flavoenzyme that is a soluble fumarate reductase related to the membrane-bound enzymes from other bacteria. Biochem 31, 12132- 12140.

Peck, H. D., Jr, Deacon, T. E. \& Davidson, J. T. (1965). Studies on adenosine- 5 -phosphosulfate reductase from Desulfovibrio desulfuri- cans and Thiobacillus thioparus. I. The assay and purification. Biocbim Biopbys Acta 96, 429-446.

Phillips, M. K., Hederstedt, L., Hasnain, S., Rutberg, L. \& Guest, J. R. (1987). Nucleotide sequence encoding the flavoprotein and iron-sulfur protein subunits of the Bacillus subtilis PY 79 succinate dehydrogenase complex. $J$ Bacteriol 169, 864-873.

Reiter, W. D., Palm, P. \& Zillig, W. (1988). Transcription termination in the archaebacterium Sulfolobus: signal structures and linkage to transcription initiation. Nucleic Acids Res 16, 24452459.

Rice, D. W., Schulz, G. E. \& Guest, J. R. (1984). Structural relationship between glutathione reductase and lipoamide dehydrogenase. J Mol Biol 174, 483-496.

Robbins, A. H. \& Stout, C. D. (1989). Structure of activated aconitase: formation of the [4Fe-4S] cluster in the crystal. Proc Natl Acad Sci US A 86, 3639-3643.

Sambrook, J., Fritsch, E. F. \& Maniatis, T. (1989). Molecular Cloning: a Laboratory Manual, 2nd edn. Cold Spring Harbor, NY: Cold Spring Harbor Laboratory.

Sanger, F., Nicklen, S. \& Coulson, A. R. (1977). DNA sequencing with chain-terminating inhibitors. Proc Natl Acad Sci USA 74, 5463-5467.

Sato, S., Nakazawa, K., Hon-Nami, K. \& Oshima, T. (1981). Purification, some properties and amino acid sequence of Thermus thermophilus HB8 ferredoxin. Biochim Biophys Acta 668, 277289.

Schidlowski, M. (1986). Evolution of the early sulphur cycle. Proceedings of the International Meeting ' Geochemistry of the Earth Surface and Processes of Mineral Formation', Granada, p. 29-49.

Schierbeek, A. J., Swarte, M. B. A., Dijkstra, B. W., Vriend, G., Read, R. J., Hol, W. G., Drenth, J. \& Betzel, C. (1989). X-ray structure of lipoamide dehydrogenase from Azotobacter vinelandii determined by a combination of molecular and isomorphous replacement techniques. J Mol Biol 206, 365-379.

Schlatter, D., Waldvogel, S., Zülli, F., Suter, F., Portmann, W. \& Zuber, H. (1985). Purification, amino acid sequence and some properties of the ferredoxin isolated from Bacillus acidocaldarius. Biol Chem Hoppe-Seyler 366, 223-231.

Schreuder, H. A., van der Laan, J. M., Hol, W. G. \& Drenth, J. (1988). Crystal structure of $p$-hydroxybenzoate hydroxylase complexed with its reaction product 3,4-dihydroxy-benzoate. $J$ Mol Biol 199, 637-648.

Schröder, I., Gunsalus, R. P., Ackrell, B. A. C., Cochran, B. \& Cecchini, G. (1991). Identification of active site residues of Escherichia coli fumarate reductase by site-directed mutagenesis. $J$ Biol Chem 266, 13572-13579.

Schröder, J. \& Klink, F. (1991). Gene for the ADP-ribosylatable elongation factor 2 from the extreme thermoacidophilic archaebacterium Sulfolobus acidocaldarius. Eur J Biocbem 195, 321-327.

Speich, N. \& Trüper, H. G. (1988). Adenylylsulphate reductase in a dissimilatory sulphate-reducing archaebacterium. J Gen Microbiol 134, 1419-1425.

Stetter, K. O., Lauerer, G., Thomm, M. \& Neuner, A. (1987). Isolation of extremely thermophilic sulfate reducers : evidence for a novel branch of archaebacteria. Science 236, 822-824.

Stetter, K. O. (1988). Archaeoglobus fulgidus gen. nov., sp. nov.: a new taxon of extremely thermophilic archaebacteria. Syst Appl Microbiol 10, 172-173.

Stille, W. \& Trüper, H. G. (1984). Adenylylsulfate reductase in some new sulfate-reducing bacteria. Arch Microbiol 137, 145-150. 
Stout, G. H. (1988). 7-Iron ferredoxin revisited. J Biol Chem 263, 9256-9260.

Takakuwa, S. (1992). Biochemical aspects of microbial oxidation of inorganic sulfur compounds. In Organic Sulfur Biochemistry: Biochemical Aspects, pp. 1-43. Edited by S. Oae \& T. Okuyama. Boca Raton: CRC Press.

Trower, M. K., Marshall, J. E., Doleman, M. S., Emptage, M. H. \& Sariaslani, F. S. (1990). Primary structure of a $7 \mathrm{Fe}$ ferredoxin from Streptomyces griseus. Biochim Biopbys Acta 1037, 290-296.

Trüper, H. G. (1982). Microbial processes in the sulfur cycle through time. In Mineral Deposits and the Evolution of the Biosphere, pp. 5-30. Edited by H. D. Holland \& M. Schidlowski. Berlin: Dahlem Conferences, Springer Verlag.

Trüper, H. G. (1989). Physiology and biochemistry of phototrophic bacteria. In Autotropbic Bacteria, pp. 267-281. Edited by H. G. Schlegel \& B. Bowien. Madison: Science Tech Publishers/Berlin: Springer Verlag.
Vik, S. B. \& Hafeti, Y. (1981). Possible occurrence and role of an essential histidyl residue in succinate dehydrogenase. Proc Natl Acad Sci USA 78, 6749-6753.

Wierenga, R. K., Terpstra, P. \& Hol, W. G. (1986). Prediction of the occurrence of the ADP-binding $\beta \alpha \beta$-fold in proteins, using an amino acid sequence fingerprint. $J$ Mol Biol 187, 101-107.

Wood, D., Darlison, M. G., Wilde, R. J. \& Guest, J. R. (1984). Nucleotide sequence encoding the flavoprotein and hydrophobic subunits of the succinate dehydrogenase of Escherichia coli. Biochem J 222, 519-534.

Zillig, W., Klenk, H. P., Palm, P., Pühler, G., Gropp, F., Garret, R. A. \& Leffers, H. (1989). The phylogenetic relations of DNAdependent RNA polymerases of archaebacteria, eukaryotes and eubacteria. Can J Microbiol 35, 73-80.

Received 4 October 1993; revised 20 December 1993; accepted 7 January 1994 